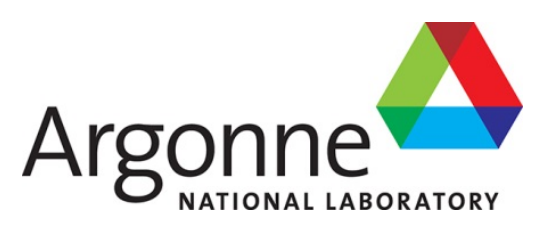

ANL/NE-16/37

\title{
Cristallini Material Review and Selection
}

Project: FY16-AN-PD2Lb-WP316

Nuclear Engineering Division 
About Argonne National Laboratory

Argonne is a U.S. Department of Energy laboratory managed by UChicago Argonne, LLC under contract DE-AC02-06CH11357. The Laboratory's main facility is outside Chicago, at 9700 South Cass Avenue, Argonne, Illinois 60439. For information about Argonne and its pioneering science and technology programs, see www.anl.gov.

\section{DOCUMENT AVAILABILITY}

Online Access: U.S. Department of Energy (DOE) reports produced after 1991 and a growing number of pre-1991 documents are available free via DOE's SciTech Connect (http://www.osti.gov/scitech/)

Reports not in digital format may be purchased by the public from the National Technical Information Service(NTIS):

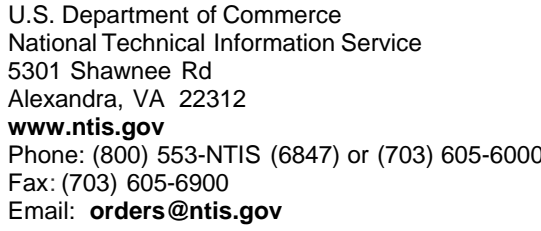

Reports not in digital format are available to DOE and DOE contractors from the Office of Scientific and Technical Information (OSTI):

U.S. Department of Energy

Office of Scientific and Technical Information

P.O. Box 62

Oak Ridge, TN 37831-0062

www.osti.gov

Phone: (865) 576-8401

Fax: (865) 576-5728

Email: reports@osti.gov

\section{Disclaimer}

This report was prepared as an account of work sponsored by an agency of the United States Government. Neither the United States Government nor any agency thereof, nor UChicago Argonne, LLC, nor any of their employees or officers, makes any warranty, express or implied, or assumes any legal liability or responsibility for the accuracy, completeness, or usefulness of any information, apparatus, product, or process disclosed, or represents that its use would not infringe privately owned rights. Reference herein to any specific commercial product, process, or service by trade name, trademark, manufacturer, or otherwise, does not necessarily constitute or imply its endorsement, recommendation, or favoring by the United States Government or any agency thereof. The views and opinions of document authors expressed herein do not necessarily state or reflect those of the United States Government or any agency thereof, Argonne National Laboratory, or UChicago Argonne, LLC. 


\section{Cristallini Material Review and Selection}

\section{Project: FY16-AN-PD2Lb-WP316}

prepared by

Nicholas Smith, Joseph Savina, Andrew Hebden

Nuclear Engineering Division, Argonne National Laboratory

$9 / 30 / 16$ 



\section{EXECUTIVE SUMMARY}

The creation of a handheld unit to utilize the Cristallini method of uranium hexafluoride sampling requires the identification and qualification of suitable substrate materials. These materials will need to quickly and completely react with the process gas, resist vapor locking under vacuum, while being relatively inexpensive and homogeneous.

Two forms of powdered alumina have been chosen for a head-to-head comparison during upcoming uranium hexafluoride tests. Both materials have shown ideal uptake characteristics during tungsten hexafluoride tests with a high loading capacity and no measureable breakthrough. They have also been shown to work well at vacuums below 10 Torr, are commercially available and inexpensive. In addition, two possible hydrogen fluoride trapping materials, sodium fluoride and saturated calcium carbonate, have been identified for further testing. 


\section{CONTENTS}

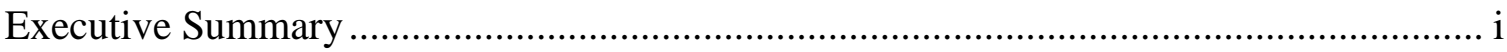

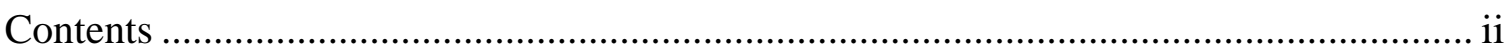

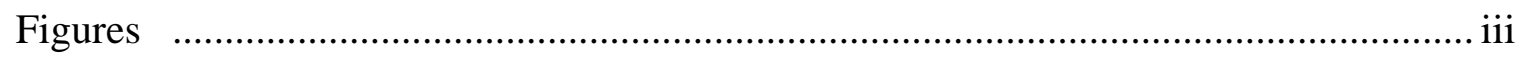

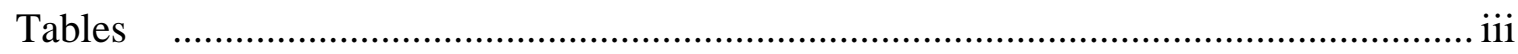

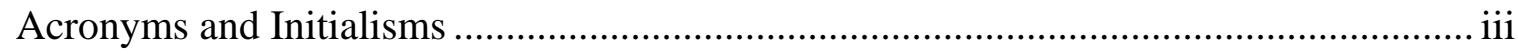

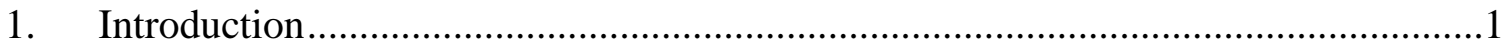

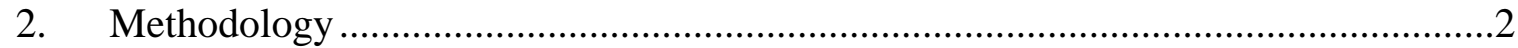

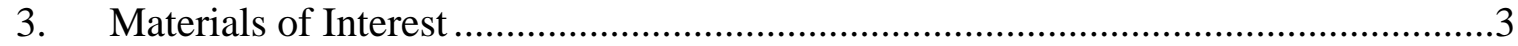

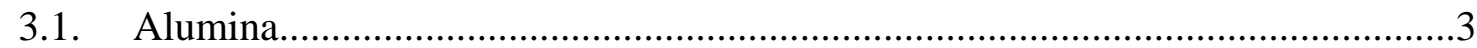

3.2. Calcium Salts .......................................................................................

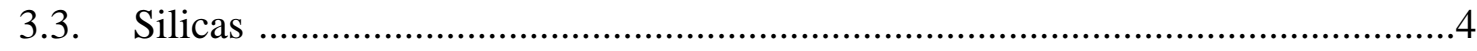

3.4. Sodium Fluoride...................................................................................4

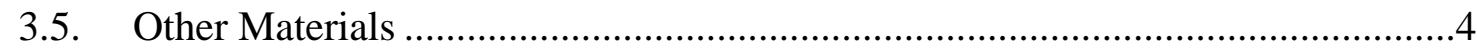

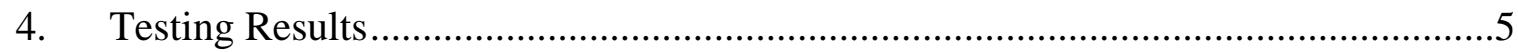

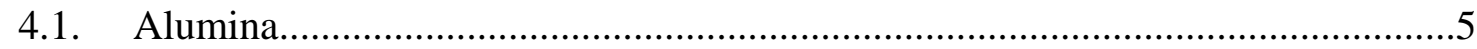

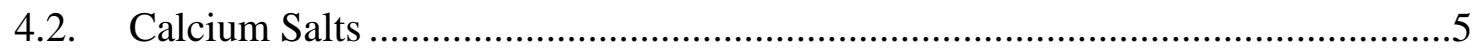

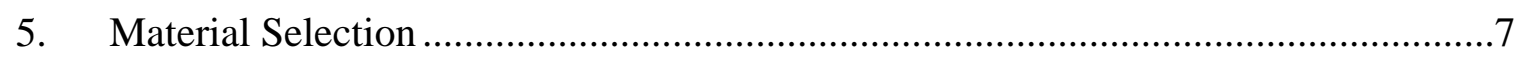

5.1. Uranium Hexafluoride Capture.................................................................

5.2. Hydrogen Fluoride Trapping ................................................................

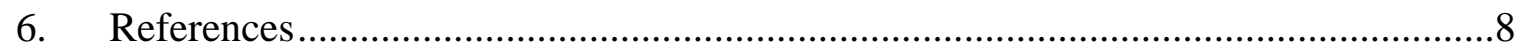




\section{FIGURES}

Figure 1 - Testing Rig and Sampler (V.0) .................................................................. 2

Figure 2 - Representative FLIR images of each material type ........................................... 6

\section{TABLES}

Table 1 - Information for aluminum oxides tested ..................................................... 5

Table 2 - Representative ICP-MS results for Alumina sample sets..................................... 5

\section{ACRONYMS AND INITIALISMS}

ANL

Argonne National Laboratory

DOE Department of Energy

FLIR Forward Looking Infrared

GCEP Gas Centrifuge Enrichment Plant

ICP-MS Inductively Coupled Plasma Mass Spectrometry

NNSA National Nuclear Security Administration 


\section{INTRODUCTION}

In order to collect samples from a gaseous centrifuge enrichment plant (GCEP) for destructive analysis to verify enrichment and impurities, samples of uranium hexafluoride $\left(\mathrm{UF}_{6}\right)$ must be taken. The standard method for this sampling is to collect a liquid sample during a homogenization operation or to sample the gaseous head space with a cryogenic collection. Both of these methods collect more material than is needed for the analysis [1]. The Cristallini method is an improvement on the gas phase collection that collects the $\mathrm{UF}_{6}$ as an inert salt on an alumina substrate using a passive vacuum [2]. This project, funded by the DOE-NNSA Office of Nuclear Nonproliferation, aims to adapt the Cristallini method to use an active vacuum system thus creating a man-portable system that can be introduced into a GCEP not currently outfitted with a standalone Cristallini setup.

The selection of a suitable substrate material is a crucial component of this handheld Cristallini implementation. The selected material needs to have several physical properties that lend to collection of the sample while not impeding the vacuum collection system or presenting an intrinsic hazard. In the traditional Cristallini setup, large alumina blocks were used as the adsorbent material in the fluorothene tube. However, the handheld system relies on an active vacuum and therefore requires materials that will not vapor lock when placed under vacuum. In addition, the material must have such a high surface area that the entire hexafluoride sample will be trapped within the sample volume, i.e., there can be no breakthrough even when a large amount of hexafluoride gas (a few grams) is passed through the trap in a very short time (0.5-5 minutes).

The trap material must react strongly with $\mathrm{UF}_{6}$ either by trapping the gas in pores or reacting with it to create a non-volatile uranium compound. Recovery of the uranium from the material should be facile and not interfere with eventual isotopic analysis. Other strong considerations for material properties include its price, chemical stability, grain size, porosity, and the formation of undesirable byproducts after reaction with $\mathrm{UF}_{6}$.

The purpose for this material is to provide distinct advantages over current sample collection methods to the inspector. First, the samples will be collected as inert salts eliminating the administrative burden of transporting $\mathrm{UF}_{6}$ gas. Second, the samples are expected to be collected much quicker than is currently feasible; sample collection times are estimated to be no more than 10 minutes as opposed to upwards of 60 minutes for cryogenic collection [2]. Therefore, the ability to quickly create a passively safe sample is the driver for material selection and reaction kinetics will be the leading indicator. 


\section{METHODOLOGY}

The process to identify and test materials started by reviewing the literature to find materials currently used to trap uranium hexafluoride or hydrogen fluoride. The materials were then tested by controlled exposure to low pressure tungsten hexafluoride (Figure 1). This test was monitored via thermal imaging and followed by destructive analysis (ICP-MS). Materials were generally tested in series to detect breakthrough from one sample to the next.

Going forward, high performing materials will be tested with the uranium system. Materials that perform well with uranium will be analyzed to determine the moisture content of the material for specification purposes. This test will be followed by an analysis of the stripped uranium solution to ensure that the materials do not add any undesirable compounds to the matrix that would interfere with analysis.

Initially, the materials were going to be tested at 1 gram of material deposited. However, as the project proceeded, the target mass was decreased to 0.1 grams. This quantity of material is more in line with what has been communicated to the project about the end user's preferences.

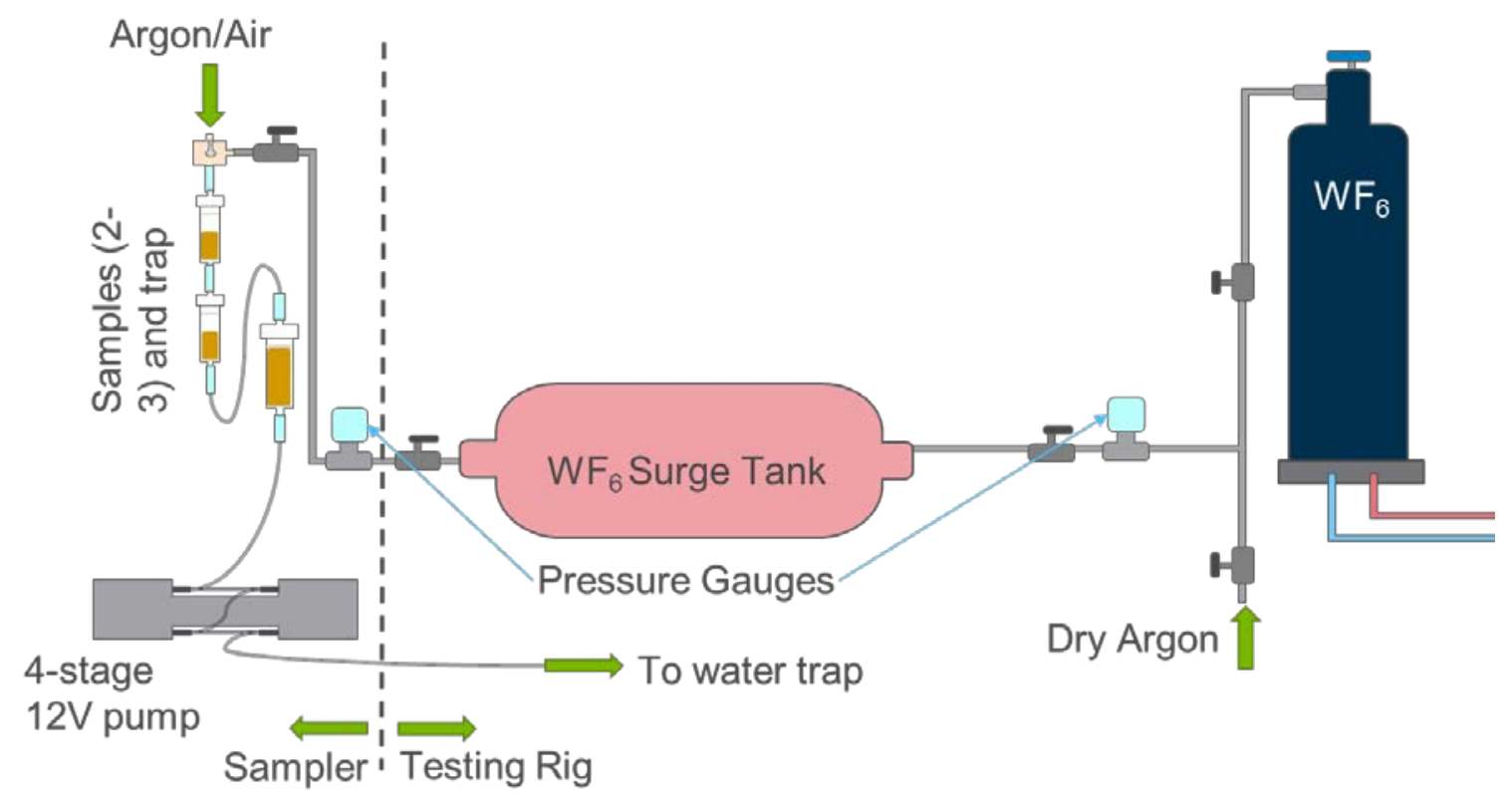

Figure 1 - Testing Rig and Sampler (V.0)

This system was used to conduct all material tests. Up to three samples of substrate were loaded into the sample locations (left). The vacuum pump would then draw $\mathrm{WF}_{6}$ from the surge tank, through the samples and trap (exhausting into a water trap). Reactions were monitored with a thermal imager. The samples were then put back under vacuum, sealed and analyzed. 


\section{MATERIALS OF INTEREST}

A literature search was performed in order to find potential candidates for a substrate material. Alumina, activated carbon, sodium fluoride, and calcium sulfate were all described in literature as successfully trapping $\mathrm{UF}_{6}$. [3] [4] [5] [6]. Additionally, calcium carbonate and calcium-gluconate were selected as potential trap materials based on their known chemical properties and uses in industry.

\subsection{ALUMINA}

Alumina is of primary interest for testing as a substrate material because as it has already been used successfully at an enrichment facility in the original Cristallini experiments [2]. The reaction between alumina and $\mathrm{UF}_{6}$ produces uranyl fluoride $\left(\mathrm{UO}_{2} \mathrm{~F}_{2}\right)$, aluminum fluoride $\left(\mathrm{AlF}_{3}\right)$, and water $\left(\mathrm{H}_{2} \mathrm{O}\right)$ according to the following two-step reaction, with hydrogen fluoride (HF) acting as an intermediate species. The reaction is dependent on the presence of adsorbed water on the surface of the alumina (Eq. 1a-b) or on partially hydrated aluminas, i.e., $\mathrm{AlO}(\mathrm{OH})(\mathrm{Eq} .2)$.

$$
\begin{aligned}
& 3 \mathrm{UF}_{6}+6 \mathrm{H}_{2} \mathrm{O} \rightarrow 3 \mathrm{UO}_{2} \mathrm{~F}_{2}+12 \mathrm{HF} \\
& 12 \mathrm{HF}+2 \mathrm{Al}_{2} \mathrm{O}_{3} \rightarrow 6 \mathrm{H}_{2} \mathrm{O}+4 \mathrm{AlF}_{3} \\
& 3 \mathrm{UF}_{6}+4 \mathrm{AlO}(\mathrm{OH}) \rightarrow 4 \mathrm{AlF}_{3}+3 \mathrm{UO}_{2} \mathrm{~F}_{2}+2 \mathrm{H}_{2} \mathrm{O}
\end{aligned}
$$

Uranyl fluoride is a stable solid and easy to work with from a chemical perspective, but the hydrogen fluoride generated could be a health risk if the reaction kinetics with alumina are too slow. The creation of HF was deemed a manageable risk for testing purposes and alumina was considered safe enough to test as a substrate material. It is also relatively inexpensive, chemically inert in air, and can be purchased in a wide range of porosities and grain sizes. Finally, the moisture content of commercially available alumina samples can exceed $1 \%$ by mass, which should be sufficient to trap uranium hexafluoride.

In total, four different aluminas were tested that spanned a wide range of particle sizes (1 $\mu \mathrm{m}-3 \mathrm{~mm}$ ). Each material was used directly from the supplier with no pretreatment or effort to change the hydration level of the material.

\subsection{CALCIUM SALTS}

Calcium carbonate and calcium gluconate were both chosen based on their known abilities to safely neutralize $\mathrm{HF}$ in industrial processes. As the above reactions illustrate, $\mathrm{UF}_{6}$ readily reacts with water to form uranyl fluoride and HF. The two calcium compounds were chosen as potential trap materials on the basis that some amount of water would be adsorbed on materials that have been exposed to air. Furthermore, based on an evaluation of ionic bond breakage vs covalent bond rearrangement energies, the reaction kinetics for calcium carbonate and calcium gluconate should be equal to or faster than alumina, increasing the safety factor for the operator. Calcium carbonate and calcium gluconate are both inexpensive and stable in air. The compounds are also relatively safe on their own and can be purchased at high chemical purities. 


\subsection{SILICAS}

Silica materials (silicon dioxide, aluminosilicates) were considered initially but discounted due to a lack of information on the level of water that could be expected in the product. The quartz material is not known for incorporating waters of hydration in the crystal lattice, though the material can absorb atmospheric moisture into pore spaces. Newer investigative lines into silica gels, which may have larger vacuum resistant moisture contents, would allow for materials to be loaded, repeatedly, to a known moisture content. This route may be tested during the uranium hexafluoride campaign if inconsistencies are found with the alumina materials.

\subsection{SODIUM FLUORIDE}

Though used in commercial traps, sodium fluoride $(\mathrm{NaF})$ was not considered for testing as the material does not produce an inert salt product; the $\mathrm{UF}_{6}$ is captured as the adduct $\mathrm{Na}_{2} \mathrm{UF}_{8}$ and as such the transportation benefits may not be fully realized (the uranium hexafluoride can still be removed and has not been chemically inerted). Additionally, the material does not perform well at room temperature and would have to be heated to $\sim 100^{\circ} \mathrm{C}$ (to aid adsorption), adding both complexity and mass to the final apparatus.

The recovery process for uranium hexafluoride from $\mathrm{NaF}$ involves either heating the sample to $350{ }^{\circ} \mathrm{C}$ to desorb the $\mathrm{UF}_{6}$ or dissolving the loaded sample in water.[5] The first would require a specialized oven and a secondary capture of the material, while the second creates a solution with such high fluoride content that follow on analytical methods could be adversely affected.

However, the use of $\mathrm{NaF}$ has been recognized as an important material of interest as a hydrogen fluoride trap and will be investigated further in that regard. The HF trap material is an essential component of the system as it ensures operator health and safety.

\subsection{OTHER MATERIALS}

Calcium sulfate and activated carbon were found to produce dangerous compounds upon reaction with $\mathrm{UF}_{6}$. The product, $\mathrm{SO}_{2} \mathrm{~F}_{2}$, is classified as a pesticide and using the material was considered an unnecessary risk [7]. The full reaction of calcium sulfate and $\mathrm{UF}_{6}$ is as follows [4]:

$$
\mathrm{CaSO}_{4}+\mathrm{UF}_{6} \rightarrow \mathrm{CaF}_{2}+\mathrm{SO}_{2} \mathrm{~F}_{2}+\mathrm{UO}_{2} \mathrm{~F}_{2}
$$

Activated carbon reacts with $\mathrm{UF}_{6}$ to form fluorinated carbon. At high enough fluorine to carbon ratios the activated carbon becomes an explosion hazard [5]. For this reason it was also not considered for testing. 


\section{TESTING RESULTS}

Samples of various materials were loaded into polypropylene columns, secured with polypropylene frits at both ends, and weighed to determine total loaded mass. Multiple samples were then loaded into the testing rig and exposed to tungsten hexafluoride. The samples were backed by a large column of various materials to act as a HF trap (see Figure 1). The pump exhaust was directed into a water trap with a calcium carbonate solution to scrub any potential HF generated.

\subsection{ALUMINA}

Two of the alumina types tested showed promise as substrate materials. The physical characteristics of the materials are presented in Table 1.

Table 1 - Information for aluminum oxides tested

\begin{tabular}{c|cccc}
\hline Series Letter & Manufacturer & Particle size & Hydration level & Successful \\
\hline M & Sigma-Aldrich & $3 \mathrm{~mm}$ & Not Specified & Partially \\
N & Sigma-Aldrich & 150 mesh $(\sim 100 \mu \mathrm{m})$ & $\sim 1.5 \%$ & Yes \\
O & JT Baker & $50-200 \mu \mathrm{m}$ & $\sim 1.5 \%$ & Yes \\
P & Alfa-Aesar & $1 \mu \mathrm{m}$ & Not Specified & No \\
\hline
\end{tabular}

The $\mathrm{N}, \mathrm{O}$, and $\mathrm{P}$ series were tested first, followed by the $\mathrm{M}$ series. For the $\mathrm{M}$ series, an $\mathrm{N}$-series was used as a backstop to prevent any $\mathrm{WF}_{6}$ leakage. The $\mathrm{N}$ and $\mathrm{O}$ series showed a high retention in early tests with the bulk of the material depositing in the upper region of the sample column. The $\mathrm{M}$ series showed some ability to stop the $\mathrm{WF}_{6}$ and a larger column ( $>2$ grams) may have quantitatively reacted the $\mathrm{WF}_{6}$. The $\mathrm{P}$ series failed as all three columns showed $\mathrm{WF}_{6}$ contributions. Therefore, the $\mathrm{N}$ and $\mathrm{O}$ series were selected to move forward.

Table 2 - Representative ICP-MS results for Alumina sample sets

\begin{tabular}{c|ccc|cc}
\hline Sample & $W(\mathrm{mg})$ & $W(\mathrm{w} \%)$ & Sample & $W(\mathrm{mg})$ & $W(\mathrm{w} \%)$ \\
\hline NA-1-1 & 98 & 4.76 & PA-1-1 & 41 & 2.00 \\
NA-1-2 & 0 & $<0.02$ & PA-1-2 & 39 & 1.99 \\
NA-1-3 & 0 & $<0.02$ & PA-1-3 & 9 & 0.42 \\
& & & & & \\
OA-1-1 & 110 & 5.18 & MA-1-1 & 74 & 3.43 \\
OA-1-3 & 0 & $<0.02$ & NA-2-3 & 6 & 0.28 \\
OA-1-2 & 0 & $<0.02$ & & & \\
\hline
\end{tabular}

\subsection{CALCIUM SALTS}

The calcium salts underperformed versus expectations as they are used commercially to scrub HF from process streams. Initially, the larger amount of tungsten $(1.0 \mathrm{~g})$ was deposited on the samples, resulting in 65-85\% of the tungsten passing through the samples and being deposited in the water trap. However, the results did not significantly improve when the smaller target mass was used $\left(\sim 0.1 \mathrm{~g} \mathrm{WF}_{6}\right)$; though the calcium carbonate showed a high retention, $\sim 90 \%$ of the small charge was retained; the reaction kinetics were still slow. 


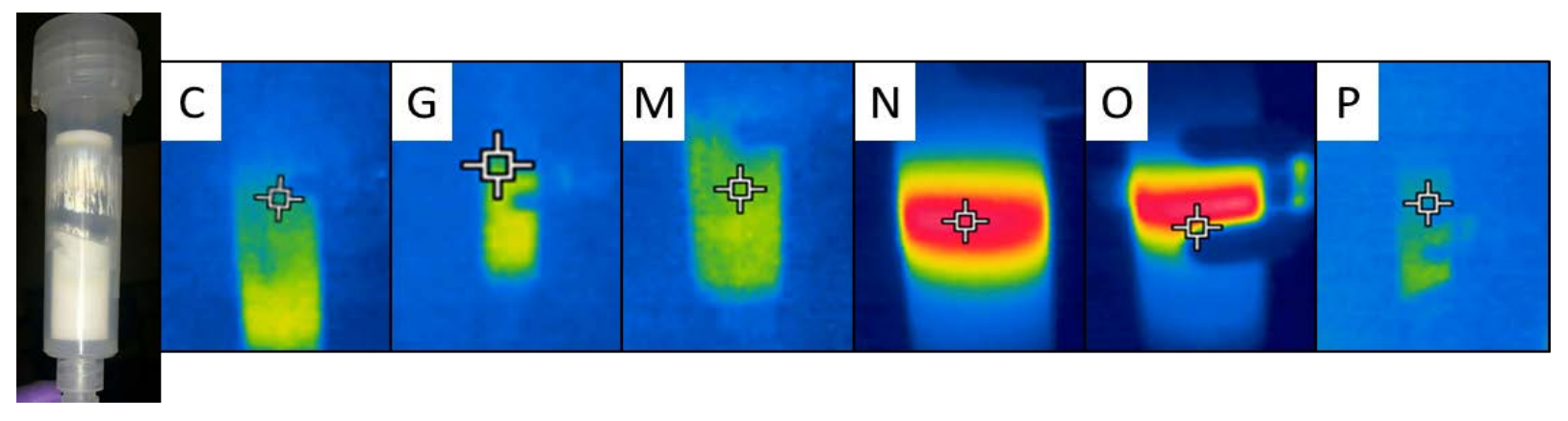

Figure 2 - Representative FLIR images of each material type

Key: C, G - calcium salts; M-P - aluminas. A full color example image of the testing columns is provided (far left) for comparison. The FLIR images show where in the columns the material is deposited; C, G, M, P show distributed adsorption indicating slow reaction kinetics while $\mathrm{N}$ and $\mathrm{O}$ show highly localized indicative of fast reaction kinetics.

As the entire substrate would be dissolved during recovery possibly complicating follow on analyses, the materials were not ideal for trapping hexafluorides but were evaluated for completeness. The materials were also evaluated as HF trap materials, though definitive tests have not been designed to measure their performance with respect to HF capture. Figure 2 shows the relatively low ability of the calcium salts to aggressively stop the hexafluoride and, anecdotally, HF was observed reacting in the vacuum pump effluent water trap suggesting that the HF passed through the system un-reacted. 


\section{MATERIAL SELECTION}

\subsection{URANIUM HEXAFLUORIDE CAPTURE}

The alumina powders at 100 micron particle size performed the best. Surprisingly, smaller grains (1 micron) expected to have a large surface area, and thusly a faster reaction, did not perform well. This is possibly due to the grains not containing enough water to be an effective trap material. Further work to standardize the alumina powders will be performed with uranium samples. This will involve repeated sampling to ensure consistency of materials and determination of possible matrix effects.

\subsection{HYDROGEN FLUORIDE TRAPPING}

Upon discussion of the project with a GCEP operator, sodium fluoride was suggested to act as a hydrogen fluoride trap as it is used in the operator's facility in that capacity. This trap material would consist of NaF pellets (or powder cartridges) on the pump inlet, outlet or both. Neutralizing the gaseous HF has also been proposed by passing the pump effluent through a saturated solution of calcium carbonate in a disposable de-misting cartridge that could be left at the inspection site. The by-products of the reaction are calcium fluoride and carbonic acid, both relatively benign compounds that could be treated as a chemical waste. 


\section{REFERENCES}

International Atomic Energy Agency, "Manual on safe production, transport, 1] handling and storage of uranium hexafluoride, IAEA-TECDOC-771," International Atomic Energy Agency, Vienna, Austria, 1994.

E. Galdoz, A. Esteban, O. Cristallini, J. A. Perrotta and , "UF6 Sampling Method

2] Using Alumina," in Annual Meeting Proceedings of the Institute of Nuclear Materials Management, Nashville, Tennessee, 2008.

S. Schuman and N. Nutley, "Method of Recovering Uranium Hexafluoride," U.S.P. 3] Office, The United States of America as represented by the United States Energy Research and Development Administration., 1975.

S. Jury, "Recovery of Uranium from Gas Mixture". United States Patent 4] US3125409 A, 1964.

G. D. Del Cul, L. D. Trowbridge, L. M. Toth and J. N. Fiedor, "Some investigations 5] of the reaction of activated charcoal with fluorine and uranium hexafluoride," Journal of Fluorine Chemistry, pp. 137-148, 2000.

R. M. Schultz, W. E. Hobbs, J. L. Norton and M. J. Stephenson, "Sorbent Selection

6] and Design Considerations for Uranium Trapping, K/ET-5025," Oak Ridge Gaseous Diffusion Plant, Union Carbide Corp., Oak Ridge, Tennessee, 1981.

United State Environmental Protection Agency, "Sulfuryl fluoride Results - AEGL

7] Program," 31 August 2016. [Online]. Available: https://www.epa.gov/aegl/sulfurylfluoride-results-aegl-program. 



\section{Argonne}

Nuclear Engineering Division

Argonne National Laboratory

9700 South Cass Avenue, Bldg. 205

Argonne, IL 60439

www.anl.gov 